AperTO - Archivio Istituzionale Open Access dell'Università di Torino

\title{
Keeping it natural? challenging indoorization in Italian rock climbing
}

\section{This is the author's manuscript}

Original Citation:

Availability:

This version is available http://hdl.handle.net/2318/1728252

since 2020-02-19T17:55:14Z

Published version:

DOI:10.1080/11745398.2018.1561307

Terms of use:

Open Access

Anyone can freely access the full text of works made available as "Open Access". Works made available under a Creative Commons license can be used according to the terms and conditions of said license. Use of all other works requires consent of the right holder (author or publisher) if not exempted from copyright protection by the applicable law. 


\section{Keeping it natural? Challenging indoorisation in Italian rock-climbing.}

Raffaella Ferrero Camoletto ${ }^{a *}$ and Davide Marcelli ${ }^{b}$

${ }^{a}$ Department of Cultures, Politics and Society, University of Turin, Turin, Italy;

${ }^{b}$ Indipendent researcher, Turin, Italy

Raffaella Ferrero Camoletto \& Davide Marcelli (2020) Keeping it natural? challenging indoorization in Italian rock climbing, Annals of Leisure Research, 23:1, 34-51, DOI: 10.1080/11745398.2018.1561307

*Correspondence detail: raffaella.ferrerocamoletto@unito.it 


\section{Keeping it natural? Challenging indoorisation in Italian rock-climbing.}

The article explores the transformation of rock-climbing in a North-Western Italian region, paying attention to need for "keeping it natural" (echoing Wheaton and Beal 2003) in the struggle for subcultural authenticity among climbers.

Like other nature sports such as rafting, skydiving and surfing, rock-climbing has been affected by processes of indoorisation (Van Bottenburg and Salome 2010) and sportivisation (Aubel 2002; Suchet 2011), changing the sites for practising from mountain rocks to artificial walls.

Adopting a post-subcultural analytical perspective (cfr. Wheaton 2007) on climbing as a nature sport, and drawing upon in-depth interviews with novices, experts and professional climbers and upon participant observation in some climbing sites (both natural and artificial walls, contests, gatherings, etc.), the article will focus on how practitioners construct their authenticity as climbers and establish intra-group hierarchies by using, and giving meaning to, the naturalness of their practice.

Keywords: Rock-climbing, nature sports, indoorisation, nature, authenticity 


\section{Introduction}

In many countries nature sports have undergone development and expansion in terms of participants and of services and commodities (Melo and Gomez 2017; Corneloup and Bourdeau 2004). Rock climbing is often grouped within this category, together with activities such as surfing, white water kayaking, backcountry skiing, assuming that those practices share some common features.

Krein (2014) outlines two core dimensions of nature sports: first, nature must play a central role as opponent/competitor or partner/teammate of the human actors involved. Secondly, the kind of nature involved is what he names "natural features", that is any part of natural world that has not been shaped by, or is not under the control of, human action and that can be easily identified, for example in maps, guidebooks or sport handbooks. As a consequence, what distinguishes nature sports is that "the features with which athletes interact are either changing as in the case of sports that take place in water, or are experienced as changing as the athlete moves through them, as in rock climbing" (2014, 198). This means that to apply the label of nature sport it is not sufficient that a sport practice takes place in a non-urban and outdoor environment: nature must be the main subject of the interaction.

Rock climbing may be interpreted as an exemplary case of a "nature sport" since on the one hand "it is very clear that rock climbing is about the climber's interaction with the rock" (Krein 2014, 195), while on the other hand cliffs, boulders, rock walls and even particular rock routes and crags are recognizable within international and local climbers' communities and mapped and described in detail.

However, similarly to other nature sports, rock climbing has undergone a double process of indoorisation (Van Bottenburg and Salome 2010) and sportivisation (Challeat 
2014). The aim of the paper is to analyse how a sample of climbers (from different specialities as well as different levels of expertise) active in Piedmont, North-Western Italy, claim authenticity for their practices (Wheaton 2007) by making various appeals to "nature". We will show how nature is evoked and signified: as a matter of the environment in which the practice takes place, and entailing the way the body is involved. In so doing, we will show how, in climbers' narratives, rock climbing is still perceived as a nature sport.

\section{Indoorisation of climbing and authenticity: a review}

Like other nature sports such as rafting, skydiving and surfing, rock-climbing has been affected by processes of indoorisation, that is "the movement of adventurous, outdoor sports to artificial (most indoor) settings" (Van Bottenburg and Salome 2010, 70), like artificial climbing walls, and sportivisation (Aubel 2002, 2005; Suchet 2011; Challeat 2014), with a distinction between "adventure climbing " and "sport climbing", together with new specialities (like bouldering), and the diffusion of formal sport competitions (mainly indoor) among climbers.

The pluralisation of the ways of climbing entails a mastery of various techniques and body skills and the valorisation of different sensations and experiences (Kulczycky 2014). The emergence and co-existence of a variety of climbing activities and styles has triggered a debate, among both participants and researchers, about what a "real climber" (Kiewa 2002) is.

The issue of authenticity has been widely discussed in various streams of literature (for a recent review on action sports, see Giannoulakis 2016). Transversal to these perspectives, authenticity has been interpreted as a social construction of symbolic boundaries rather than an objective category (Williams and Copes 2005, 76), resulting 
from the interaction between those who make the authenticity work and those who are in the position of rejecting the authenticity claim (Peterson 2005) ${ }^{\mathrm{i}}$.

Discussing authenticity claims among rock climbers, therefore, entails investigating the various ways in which "discourses of authenticity are used strategically by self-identified core members to identify and marginalize other participants." (Donnelly $2006,220)^{\mathrm{ii}}$, where core members may include not only sport practitioners, but also rockclimbing service providers ${ }^{\text {iii }}$.

Kiewa (2002) identified a set of features defining the symbolic boundaries of the "real climber", opposed to the "pretender": in her qualitative research on self-defined Australian traditional rock climbers, the core dimension is the "go-for-it" attitude, the enjoyment of climbing for its own sake. One of the markers of this attitude is the adoption of exploratory behaviour, implying a personal search for climbing sites and criticism of the commercialisation of climbing guidebooks and adventure tourism agencies.

More recently, two further empirical studies have explored the definition of authenticity among traditional or adventure climbers.

Bogardus (2012) focussed on the recent history of climbing, with the arrival of the "French style" in the USA as a fruitful example of the struggle for the definition of legitimacy and authenticity. Opposite to the previously prevailing style in the USA, which was based upon the improvisation of an ascent from the ground up, French climbers adopted bolts as a protection to be able to climb the most difficult routes more safely. The debate concerning the use of bolt protection, the so-called "bolt wars", showed the opposition of two different sources of authentication of the practices: voluntary and mastered risk for the American traditional climbers versus athletic and technical skills for French sport climbers. Traditional rock climbers interviewed by Bogardus tended to attribute more value to risk in the never-fully-under-control natural environment, thereby 
defining their practices as more authentic than those of sport climbers.

Another example of the importance of nature in authenticity claims is provided by Rickly-Boyd (2012): focussing on a popular climbing site in the USA, Red River Gorge, Kentucky, she described a specific type of "lifestyle climbers" whose distinctiveness is based upon their sober way of life devoting all their resources to climbing, and upon their departure from a merely touristic approach to travelling. Recalling Wang's (1999) notion of “existential authenticity", Rickly-Boyd detected in lifestyle climbers a specific way of accounting for the authenticity of their practice, which can be summarised in the symbolic word "dirtbagging": "Being a dirtbag is not only a discursive identity, but also a performance of dedication, sacrifice, and lifeways" (2012, 97), in which a relationship with the outdoor environment and with the climber's embodied experience is central.

These three studies explicitly connect the definition of authenticity in climbing with a direct interaction with nature. The reference to outdoor life seems to remain a central discourse in "keeping it real" (Wheaton and Beal 2003). However, since those studies focussed only on one side of the coin, that is the perspective of traditional and adventure climbers, the impact of indoorisation -and of sportivisation- in the battle for the authenticity of different ways of climbing remains partially overlooked.

In this perspective, an important contribution is the work of Salome and Van Bottenburg (Salome 2010; Van Bottenburg and Salome 2010; Salome and Van Bottenburg 2012) on the indoorisation of some lifestyle sports (skydiving, skiing, diving, white water sports, and also climbing) in the Netherlands. In her 2010 article, Salome pointed out that the relocalisation of lifestyle sports from natural to artificial/indoor s (in the case of climbing, from mountain rocks to indoor artificial walls) had also promoted a double shift in their authenticity claims. 
The first shift is "from nature to scenery": if at the beginning there was the effort, in the structure and material of artificial settings, to simulate the natural environment as the main source of authenticity, gradually the reference to nature lost its importance, so that "nature is now defined as a convertible and adjusted scenery" (Vanreusel, 2002, 185, cit in Salome 2010, 75). The authenticity of the practice seemed therefore to be decoupled from the naturalness of the context and to be associated with the experiential richness provided by indoor facilities. In other words, "as these sports can be experienced in controlled and predictable environments, principles such as risk-taking and sensationseeking are less relevant, as are the feelings of interacting with nature and escaping from reality" (Salome and Van Bottenburg 2012, 24).

A second shift displaced the power to define authenticity from participants to the suppliers of indoor facilities and services, who would tend to acknowledge and welcome more inclusive and plural forms of participation in lifestyle sports, thereby downplaying the previous struggles for the construction of hierarchies among practitioners.

Another proof of the transformation under way is that the strife for authenticity seemed to decline also among indoorised lifestyle sports practitioners: Salome and Van Bottenburg (2012), adopting a mixed-method approach (on-line questionnaires and indepth interviews with indoorised lifestyle sports participants in the Netherlands), constructed a typology classifying "exercisers" (29\%), "experiencers" (36\%) and “exceeders” (35\%). "Exercisers" (among whom rock climbers are overrepresented, 46\%) are those who practise their sports mostly indoors, for a mixture of practical (the convenience of the site), health-oriented (keeping fit) and social (meeting other people) reasons. "Experiencers" (more represented among kayaking, scuba diving and skydiving participants), on the contrary, are those who give value to sensations like freedom, kicks, flow and to the natural environment: "For this group, the experience of being outdoors 
and the feeling of being at one with nature are essential elements of lifestyle sports" (Salome and Van Bottenburg 2012, 32). However, despite their clear preference for natural environments, the majority of this category acknowledges the positive side of artificial facilities in providing easier, more convenient access to the practice. Finally, "exceeders" (among whom climbers are widely represented) combine the convenience of training in artificial settings with the pleasure of experiencing outdoor settings.

Salome and Van Bottenburg's research seems to lead to the conclusion that in new indoorised commercialised lifestyle sports, including rock climbing, the source of authenticity has deviated from the reference to naturalness, and that the dichotomy between indoor and outdoor practices has declined, moving towards increasing legitimation, and often a widespread combination of both ways of practising.

In the following sections we will further investigate the impact of indoorisation on the way rock climbers make sense of their practice. We will try to address some research questions: in the Italian context, is the reference to nature still relevant among practitioners attending also indoor climbing halls? And does the reference to nature, however defined, still work at making boundaries and hierarchies among different subgroups of practitioners?

\section{Context and methods}

The starting point of our article is to discuss the results of Salome and Van Bottenburg's recent work on the impact of indoorisation on the construction of the authenticity of indoorised lifestyle sport. We identify two limitations in their research.

The first is that little room had been given to how participants in indoorised sports construct the meaning of their experience and account for its authenticity: Salome (2010) focussed exclusively on suppliers of indoor sport facilities (18) and federations (7), while Salome and Van Bottenburg (2012), despite exploring the perspective of participants, 
relied on a quantitative (372 on-line questionnaires, among whom $76 \%$ are practising rock climbing) more than on a qualitative (only 8 in-depth interviews, of whom 4 rock climbers) data set.

On the contrary, in order to explore the transformations in the role given to "nature" in rock climbers' authenticity claims, we chose to focus on a larger and more comprehensive sample of both participants (on the basis of gender, age and level of sport experience) and suppliers of sport and indoor climbing facilities (indoor climbing hall managers, sport climbing instructors, route setters and referees).

The second limitation is the specificity of the investigated context: the Netherlands, because of their flat orographical configuration, cannot provide easy access to natural sites for many of the lifestyle sports considered. This is particularly the case of rock climbing.

On the contrary, the context of our research, Turin, has a peculiar profile: it is a metropolitan city (in 2016, about 900.000 inhabitants in the municipal area, and about 2.300.000 in the whole metropolitan area, including 316 municipalities), but it is surrounded by nearby mountains (mainly the Alps, about 1 hour by car, with coaches and train services). Notwithstanding its closeness to outdoor climbing sites, in the Turin metropolitan area there are 6 indoor climbing halls and some smaller indoor climbing facilities. Moreover, Turin has been one of most important centres in the history of Italian mountaineering and climbing. It is the city where the Club Alpino Italiano (CAI), the national association of mountaineering, was founded in 1863 , and where some of the more famous Italian mountain climbers were born and grew up. The surrounding mountains hosted the first international sport climbing competition in 1985 , fostering the birth of the FASI (Federazione di Arrampicata Sportiva Italiana), the Italian Federation 
of Sport Climbing. Nowadays, Turin is also the headquarters of the Streetboulder Italia association.

Our empirical data are verbatim transcriptions of 40 in-depth interviews, ranging from 40 minutes to 120 minutes of audio-recording. The collected interviews are part of three different, albeit interconnected, research projects (two Masters dissertation research projects $^{\text {iv }}$ and a follow-up research carried out by the authors), and were conducted between September 2015 and October 2017.

The interviewees were selected and recruited through a combination of purposive, emergent, snowballing and convenience sampling (Patton 1990). All the interviewees, except one (a professional mountain guide living in the Aosta Valley), live in the Turin metropolitan area. Their age ranges from 18 to 56, and their level of climbing expertise differs from suppliers of indoor and sport climbing facilities (10, of whom 2 managers of indoor climbing halls, 2 referees and 6 instructors of sport climbing) to sport climbing athletes (3), expert amateurs (11), medium-experienced amateurs (13) and novice amateurs $(3)^{\mathrm{v}}$.

Table 1. Interviewee information

\begin{tabular}{|l|l|l|l|l|l|}
\hline Int & Pseudonym & Age & Gender & Level of expertise & Participant type \\
\hline 1 & Ana & 21 & M & Expert amateur & Indoor \& outdoor \\
\hline 2 & Camilla & 27 & F & Medium-experienced amateur & Indoor \& outdoor \\
\hline 3 & Ernesto & 21 & M & Instructor and athlete & Indoor \& outdoor \\
\hline 4 & Enrica & 37 & F & Expert amateur & Indoor \& outdoor \\
\hline 5 & Giada & 24 & F & Novice amateur & Indoor \& outdoor \\
\hline 6 & Ilenia & 18 & F & Athlete & Indoor \& outdoor \\
\hline 7 & Mattia & 24 & M & Expert amateur & Indoor \& outdoor \\
\hline 8 & Gustave & $27-29$ & M & Instructor and route-setter & Mainly indoor \\
\hline 9 & Leonzio & 23 & M & Athlete & Indoor \& outdoor \\
\hline
\end{tabular}




\begin{tabular}{|c|c|c|c|c|c|}
\hline 10 & Maria & 22 & $\mathrm{~F}$ & Medium-experienced amateur & Mainly indoor \\
\hline 11 & Michele & 25 & $\mathrm{M}$ & Medium-experienced amateur & Mainly indoor \\
\hline 12 & Mirco & 27 & $\mathrm{M}$ & Expert amateur & Indoor \& outdoor \\
\hline 13 & Riccardo & 23 & $\mathrm{M}$ & Medium-experienced amateur & Mainly outdoor \\
\hline 14 & Valentina & 24 & $\mathrm{~F}$ & Medium-experienced amateur & Mainly outdoor \\
\hline 15 & Asia & 26 & $\mathrm{~F}$ & Instructor & Mainly outdoor \\
\hline 16 & Antonia & 45 & $\mathrm{~F}$ & Expert amateur & Mainly outdoor \\
\hline 17 & Barbara & 28 & $\mathrm{~F}$ & Expert amateur & Indoor \& outdoor \\
\hline 18 & Caterina & 34 & $\mathrm{~F}$ & Expert amateur & Mainly indoor \\
\hline 19 & Daniela & 41 & $\mathrm{~F}$ & Medium-experienced amateur. & Mainly indoor \\
\hline 20 & Ester & 49 & $\mathrm{~F}$ & Referee and instructor & Mainly indoor \\
\hline 21 & Enia & 27 & $\mathrm{~F}$ & Expert amateur & Mainly outdoor \\
\hline 22 & Francesca & 46 & $\mathrm{~F}$ & Expert amateur & Indoor \& outdoor \\
\hline 23 & Fiorenza & 21 & $\mathrm{~F}$ & Athlete & Mainly outdoor \\
\hline 24 & Lavinia & 46 & $\mathrm{~F}$ & Medium-experienced amateur & Indoor \& outdoor \\
\hline 25 & Lorenza & 28 & $\mathrm{~F}$ & Instructor & Indoor \& outdoor \\
\hline 26 & Liliana & 41 & $\mathrm{~F}$ & Medium-experienced amateur & Mainly outdoor \\
\hline 27 & Loredana & 27 & $\mathrm{~F}$ & Expert amateur & Mainly indoor \\
\hline 28 & Miriam & 26 & $\mathrm{~F}$ & Novice amateur & Mainly indoor \\
\hline 29 & Monica & 24 & $\mathrm{~F}$ & Instructor and athlete & Indoor \& outdoor \\
\hline 30 & Melania & 51 & $\mathrm{~F}$ & Medium-experienced amateur & Mainly indoor \\
\hline 31 & Martina & 53 & $\mathrm{~F}$ & Medium-experienced amateur & Indoor \& outdoor \\
\hline 32 & Piera & 56 & $\mathrm{~F}$ & Medium-experienced amateur & $\begin{array}{l}\text { Mainly indoor } \\
\text { (now) }\end{array}$ \\
\hline 33 & Stefania & 32 & $\mathrm{~F}$ & Expert amateur & Mainly outdoor \\
\hline 34 & Sonia & 50 & $\mathrm{~F}$ & Novice amateur & Mainly indoor \\
\hline 35 & Viviana & 32 & $\mathrm{~F}$ & Medium-experienced amateur & Indoor \& outdoor \\
\hline 36 & Veronica & 27 & $\mathrm{~F}$ & Medium-experienced amateur. & Mainly outdoor \\
\hline 37 & Dino & 49 & $\mathrm{M}$ & Referee and instructor & Mainly outdoor \\
\hline 38 & Cesco & 30 & $\mathrm{M}$ & $\begin{array}{l}\text { Indoor climbing hall manager and } \\
\text { route-setter }\end{array}$ & Indoor \& outdoor \\
\hline 39 & Daniele & 36 & $\mathrm{M}$ & $\begin{array}{l}\text { Indoor climbing hall manager and } \\
\text { route-setter }\end{array}$ & Indoor \& outdoor \\
\hline 40 & Pietro & 40 & $\mathrm{M}$ & Instructor & Mainly indoor \\
\hline
\end{tabular}


The empirical material available has a contains considerable internal variance due to the fact that the three research projects adopted different interview guide templates ${ }^{\mathrm{vi}}$. The issue of "nature" in the interviewees' rock climbing accounts, therefore, was not always the topic of an explicit question. Interview transcriptions were analysed using thematic analysis (Braun and Clarke 2006), being coded then analysed (Sparkes and Smith 2014): as a result, nature emerges as an multi-layered topic in almost all the narratives collected.

In the following paragraphs, we illustrate the main sub-themes according to which interviewees raise the issue of nature as a relevant topic in making sense of their rock climbing experience.

\section{Away from nature? The indoorisation of climbing}

Artificial climbing walls represent the oldest (dated back to the 60s) and best-known example of artificial facilities moving the practice from outdoor natural to indoor, purpose-built settings. The indoorisation of climbing engendered an expansion of the number of its practitioners. In Italy, the national federation of sport climbing (FASI), since its foundation in 1987, has gradually increased its participation (in 2010, 15.000 individual members and 200 sport associations).

The reasons for this success are well summarised by Eden and Barratt (2010): "Indoor climbing was originally intended to be a rainy day alternative to the outdoors, so in terms of comfort, walls protect climbers from the weather and provide indoor heating as well as cafés, social areas and shops. Walls also offer a safer introduction to the sport of climbing for beginners, away from slippery or icy surfaces during bad weather. [...] Climbing walls are also more convenient. They allow climbers to visit and train at times when they cannot get out to the crags, whether because it is dark or because they live in 
cities far away from outdoor routes and cannot drive there easily between work or family commitments." (490).

In our interviewees' accounts, we find a convergence with the reconstruction of the recent history of climbing in international literature. Originally artificial climbing walls were thought of as a safer, more accessible site for teaching and training skills to be used on rock walls. As an interviewee states:

\begin{abstract}
"The evolution, in my opinion, the first step was to shift from mountaineering to climbing, then climbing on artificial walls where you can climb in summer and winter, or attend courses any time during the day or at night. Think of the possibility of climbing as soon as you get out of the office." (Dino, referee and instructor)
\end{abstract}

Indoor climbing therefore began initially as a means to train for mountaineering. As a consequence, former artificial walls simulate natural rocks in their shape, in order to artificially reproduce how nature challenges the climber's movements.

"Artificial climbing walls were created to train people to go on the rocks. [...] Therefore the moves one reproduced indoors were the as outdoors: fingers were trained a lot, because one should be able to grab on little holds." (Gustave, instructor and route-setter)

As a result of their increasing popularity, artificial climbing facilities progressively became an essential part of rock climbing, promoting a shift to competitive events and the sportivisation of the practice (Salome 2010). Indoorisation and sportivisation of rock climbing appear to be interconnected: as it becomes a sport with its own rules, competitions and scores, sport climbing infrastructures gradually diverge from outdoor traditional climbing ones. 
Artificial walls were then re-adapted to the new specific skills, moves, combinations of moves, and muscle groups to be trained in order to join climbing competitions: climbing holds acquired new shapes and positioning, and climbing volumes (that are "those giant prism features that are attached to the wall like any other climbing hold." ${ }^{\text {vii }}$ ) emerged as a revolutionary element of route-setting, turning what was once a static, flat feature into a dynamic, changing three-dimensional space ${ }^{\text {viii }}$. Therefore not only indoor walls became more "artificial", but also sport climbing moves departed from natural climbing movements, becoming more sport-specific motor skills: the specialisation of movement responded to the need of differentiating and ranking climbers' performances during competitions. As an interviewee explains:

\begin{abstract}
"Competitions began with movements similar to those on the rocks. At some point, as many people in the know believe, it was impossible to get a pecking order on those movements. [...] Therefore route-setters started to set out-of-balance movements $[\ldots]$ where the old-school climber didn't feel comfortable and fell. [...] Reading the route, interpreting the boulder, and managing one's body have become more difficult. [...] I distinguish substantially between rock climbing and indoor climbing. Nowadays [...] moves adopted during competitions are very different from those on natural rocks. This is a little paradoxical, we start from moves which were an imitation... taken from rock climbing, then we went beyond that [...] This was the big difference; on the rock you can't have these movements because there is no boulder-like shape. Now they set volumes that you would not consider climbing on the rocks, but during a competition you must do it. [...] Compared with natural movements on the rock, this makes it less natural. But in my opinion this makes it something apart - it's not more or less natural [...] simply it's something different, a sport”. (Gustave, instructor and route-setter)
\end{abstract}

In accordance with Salome (2010), many interviewees acknowledge a decoupling of artificial settings from the natural environment as a taken-for-granted process. What makes an indoor climbing site attractive for participants is their technical features such as 
artificial walls (mainly the variety of the holds and the quality of route-settings). Therefore, a climbing site is evaluated in comparison with other artificial indoor facilities and not measured against the natural environment.

"I consider these wooden holds very kitsch, wood and stone [...] you are on an artificial wall, everything is fake, it is pointless to insert something recalling the natural $[\ldots] . "$ (Pietro, instructor)

In our sample, route-setters are particularly keen on discussing this issue, arguing that artificial walls tend to become increasingly spectacularised, with shocking colours and shapes in holds and volumes. Moreover, they tend to interpret any seeming "return to nature" (in materials, shapes, etc.) as a commercial initiative to attract new customers and to secure old ones' loyalty within an expansion not only of demand, but also of competing suppliers. The use of "natural" material (like wood or stone) is therefore a commercial and aesthetic choice more than a technical or value-oriented option.

\footnotetext{
"The guy who says 'Well, in some rock climbing gyms the route-setting is far from the rock, while in others it seems you are climbing in the Susa Valley, on cliffs". The answer is simple; I tend to set routes to please the cliff-passionate climber who is only crimping and the one who likes the boulder with little edges, where you put reverse fingers, a little old-school but no less entertaining or useful. [...] Nowadays, to make things more and more spectacular, we work on the acrobatic side of the movement, and on the scenic impact of the set holds." (Cesco, artificial climbing hall manager and route-setter)
}

"I think that brands have followed different attitudes. I saw very little holds [...] which look fake, like fake rock to be fixed on the artificial wall. [...] In that case it is an aesthetic choice, linked to pleasing, selling, providing something new." (Dino, referee and instructor) 
But indoorisation is not the whole story. In the next section, we will show how nature returns as a meaningful reference in climbers accounting of both their indoor and outdoor practice.

\section{The naturalness of climbing}

Our interviewees revealed that climbing and nature remains closely connected. However, in their accounts practitioners evoke nature not only as a specific context for their practice (nature as an outdoor environment), but as a more general frame recalling the idea of "naturalness", defining distinctive lifestyles and movements.

The first way naturalness is portrayed by the practitioners is by addressing the importance of the outdoor environment. The majority of the interviewees explicitly define climbing as an activity that should take place in a natural, thereby outdoor context, qualified by its physical traits: the boundlessness of mountain and foothill areas, along with the different variety of rocks and the listing of the most famous climbing spots are recalled in this respect. According to Kulczycky (2014), also in this case the definition of the physical dimension of a certain site, as well as its attributes, occurs both at a macro stage - described by "the broad site feature, layout and the atmosphere" $(2014,13)$ - and a micro stage because of the importance emphasis placed "on geology (e.g., rock types), routes, and holds were features influencing place-meaning the most" (ibidem).

For the above mentioned reasons, some outdoors sites become ideal and mythical compounds in the climbing collective imaginary which our practitioners draw upon in their mapping the ultimate, par excellence "Mecca spots".

"I like different sites where I come back often, they could be the Orco Valley or Finale Ligure, spots like these. But I also like to visit new places, find out new types of rock, follow strange routes." (Mattia, expert amateur) 
Sometimes interviewees construct the naturalness of their climbing destinations beyond their physical features: the key point is not where to go' within' the natural environment, but to escape from urban contexts.

"[Climbing] to me is a way to get out the city, to be surrounded by green and emptiness, to hear from nobody." (Riccardo, medium-experienced amateur)

The city as purpose-built-space, thereby fully under human control, is framed as "unnatural". Similarly, artificial climbing halls are criticized as "highly managed spaces where the majority of risks are removed or designed out, thus providing comfort through safety and security" (Eden and Barratt 2010, 490). Traditional climbing and multipitching, on the contrary, are valued as practices where risk cannot be sanitised and within which different, more demanding, physical and mental involvement are required.

\footnotetext{
"On indoor walls the worst you can do is to break an ankle because you fall badly. On the rock it depends, it ranges from breaking an ankle to endangering your life. [...] I am not just obsessed by making the grade in complete safety. [...] Those who climb outdoors are more used to going on the mountains or coping with more difficult situations, containing higher risks... I feel those climbers are closer to my attitude because they do not pay so much attention to the level of difficulty but are more interested in the adventurous side of climbing rather than the technicalities of mere sport performance.” (Mattia, expert amateur)
}

Another way of attributing naturalness to outdoor environments is by mentioning the emotional and sensorial experience they trigger. We find repeated descriptions of what the climber's body feels palpably - including the senses of touch, smell and sight - 
during climbing experiences in a wild outdoor setting. The embodied sensations work as the markers of the naturalness of the outdoors.

"I love climbing outdoors! When you feel the clean smell of the air and not the stink of the gym." (Ana, expert-amateur)

The involvement of multiple senses - evoked through the smell of the fresh air, the view of a beautiful landscape and the tactile pleasure of the real rock - is often enhanced by making reference to emotions. Respondents often outline different feelings which can be unleashed only within the natural environment: the rush triggered by the height reached or by falling; the mindfulness during outdoor climbing; and the absolute flow while topping a boulder.

"Climbing makes me feel peaceful... it makes me focus on one thing, on the rope especially. You feel the effect of the void while climbing on the rock wall. I find that climbing really clears my mind." (Enia, expert amateur)

Naturalness, in addition to the physical-environmental frame, seems to be informed by an experiential and existential dimension conveyed by the idea of a particular natural lifestyle.

Our interviewees stressed the importance of an exploratory approach (Kulczycky 2014) to climbing: this requires trying different types of rocks, not confining oneself to Mecca spots and better-known climbing sites, and constantly searching for new, noteasily-accessible places.

"I like to go to different places so I bought a van with a friend and we go around as much as we can. He is a colleague of mine, therefore when we are free we take the van and leave. This summer we went to Siena where we set several boulder and lead 
routes in a gym, with and without ropes. Then we moved on and reached Monte Amiata, climbed there and later took the ferry in Civitavecchia and went to Sardinia. [...] We came back to Turin, met other friends and hit the road again, heading for Switzerland and Austria. We travelled for over a month." (Daniele, indoor climbing hall manager and route-setter)

"[...] You make choices that most of the people do not understand. They told you: 'What the hell, you went to Thailand where there are the best beaches in the world and you looked for cliffs?'. Yes, because everyone sees these beaches and nobody has never seen the cliffs!" (Veronica, medium-experienced amateur)

Daniele and Veronica's quotes incorporate many interesting topics. While he mentions some of the well-known Mecca destinations for climbers, namely Switzerland and Austria, both also adopt an exploratory approach by reinterpreting places like Thailand, Sardinia and Monte Amiata, which are not included in climbing guidebooks, as enjoyable climbing sites. Veronica exemplifies the refusal and subversion of a touristic attitude: while normally people identify Thailand with its beaches she rather focusses her attention on cliffs as a feature usually ignored in the typical Thai postcard.

Daniele, whilst moving from one place to another, bags a lot of of spots during a single climbing trip, thereby underlining a deliberate voracious nomadism, a distinctive trait of a real climber (Kiewa 2002). However, this nomadism conveyed by the number of destinations listed and the means of transportation quoted (the van, recalling the "vanner" character in Rickly-Boyd 2012), also symbolizes a free "gypsy" spirit, a core element of a natural lifestyle.

Another component of this lifestyle is the rejection of any form of tourist facilities. Sleeping in a tent and eating low-price nutrient foods, as well as other simple-life choices, expresses the desire abstain from any form of comfort or luxury. 
"The closer a cliff or a boulder area is to nature, the more beautiful it is. You can easily set yourself up there with a tent without the necessity of camping or accommodation facilities." (Camilla, medium-experienced amateur)

"Climbing is a real lifestyle, it turn you into a gypsy. You sleep somewhere in a tent, yes, it becomes your lifestyle." (Viviana, medium-experienced amateur)

The naturalness of this gypsy lifestyle includes one more aspect: the inclination to seek ever-more- direct contact with nature by normalising and welcoming those adventurous and inconvenient elements that normal people would consider unpleasant and to be avoided (Rickly-Boyd 2012). To this aim, practitioners search for direct physical contact with the natural environment and often valorise the effects produced by the latter on their bodies - from wearing out their fingers to feeling pain in their backs because of sleeping on hard surfaces, from getting dirty because of the magnesite to wetting their shoes after having crossed a river in order to reach a boulder area.

\footnotetext{
"We can say that climbers are open-minded, they do not disdain sleeping in their knapsacks at the bottom of the cliff. They are a bit wild. We had a holiday in Spain and there were three of us in a small car. We spent fifteen days like this, two sleeping inside and one outside in rotation. Our kitchen table was the spare wheel." (Leonzio, athlete)
}

Hitherto the naturalness of climbing has been detected with reference to a physical-natural environment and to a defined lifestyle. The outdoor-indoor dichotomy has been central in this respect: at this stage, the practitioners seemed to raise another issue, a notion of naturalness as a shared attribute cross-cutting all the forms of climbing.

The act of climbing is acknowledged as a milestone in children's growth process from the quadrupedal dimension to the bipedal: climbing is defined as a basic physical 
motor scheme. Training children to climb, therefore, is attributed a healing mission to keep alive that inborn, natural gesture which would otherwise be lost in an ever-more inactive, sedentary and rationalised society. The motor scheme embodied in climbing therefore maintains and attests the strong naturalness of this practice regardless of the context.

\footnotetext{
"Climbing is one of a child's motor schemes. The child learns to climb before being able to walk because he or she has to stand up from a four-legged position, using just two of them. For this reason the baby uses its arms, so maybe it goes close to a wall and while it tries to pull itself up it is starting to climb. I think that climbing is part of... of us. Everyone, to a greater or lesser extent, is born to climb. [...] Even indoor climbing is still natural to me, whether climbing is considered as an internal natural inclination or as an activity taking place in a natural environment". (Daniele, indoor climbing hall manager and route-setter)
}

\begin{abstract}
"When someone is young, he climbs, doesn't he? Because you are a baby and you are trying to get onto your feet. Once you start growing, you begin to unlearn how to climb because you are used to standing on your feet. [...] So we can see a loss of a natural attitude we normally have had since we were children. I think that this loss can be also traced back to the flat city-life which makes us forget how to climb". (Pietro, instructor)
\end{abstract}

If the practice performs an important function allied to the physical motor scheme, at the same time the experience acquires another meaning: climbing is often described as a playful experience not only by those instructors involved in teaching children as well as by many adult practitioners.

Children tend to be introduced to climbing as a game, focussing on playing with colours and shapes of the holds to be used: in this way, the climbing motor act is developed with an immediate sense of fun and enjoyment. On the other hand, when adults approach climbing for the first time, they often seem to rediscover this playful attitude: 
the pleasure of the practice is therefore linked to becoming children again and to retrieving the natural motor scheme which their adult civilised bodies had forgotten.

"Q: When you started to climb what did you like best?

A: It felt like I was again at the playground when I was a child even though I was then 20 years old! It felt like going back to that time when only fun and games are in your mind and it was a feeling I had not felt in a long time. In my opinion the reason why climbing nowadays is becoming 'cool' is that it is like going on playing. During their lunch break 60-year-olds come to the indoor climbing hall, have fun and play. To me this is the magic formula of climbing: its playfulness. Yes, it is a real game, you are there and see a lot of coloured things, this is what attracted me the first time." (Gustave, instructor and route-setter)

\section{Back to nature: outdoor climbing as a marker of authenticity}

In traditional adventure sports, involvement in a natural setting and challenge was a core dimension of participation (Wheaton 2004): it can be looking for big waves in surfing (Beal and Smith 2010), experiencing the countryside in mtb (King \& Church 2013) or the backcountry as a masculinised sportscape in skiing (Stoddard 2011), embodying nature as a spiritual space in windsurfing (Humberstone 2011) or as an intimate companion in extreme sports (Brymer and Gray 2010).

As we have already mentioned, some scholars identify a significant shift in those lifestyle sports which have seen recent growing indoorisation (Van Bottenburg and Salome 2010): from the primacy of nature as a source of authenticity - leading to the effort to simulate the natural environment in designing artificial sport facilities - to the reinterpretation of nature as a backdrop to be staged and manufactured.

In the specific case of sport climbing in an indoor setting, Salome (2010) gave some evidence of an increasing disassociation of indoor climbing walls from natural 
rocks, witnessed by the choice of materials, colours and shapes. Moreover, she pointed at a more varied participation profile in indoor settings compared to outdoor: among indoor climbers, female and older participants tend to be more numerous. However, she also acknowledged that "there are still tensions between core members of sport culture and the new consumers. These tensions are, especially in climbing centres, an issue" (ibid., 81): for instance, "real climbers" don't train indoors on average Saturdays when children's classes are scheduled.

Our research, focussing on both indoor climbing facilities suppliers and users, provides a more articulated and non-unanimous representation of how the reference to "naturalness" still works as a boundary-marker in distinctions and hierarchies among different groups of climbers.

Indoor and sport climbing facilities suppliers (including, as we have illustrated in the methodological section, indoor climbing hall managers, instructors, route-setters and competition referees) tend to show a more positive, inclusive attitude towards not only the increasing participation in sport climbing, but also towards the pluralisation of meanings attached to it: some interviewees explicitly acknowledge the legitimacy of every way of climbing, stressing the value of freedom in interpreting the practice.

\footnotetext{
"What's beautiful in this sport is that everybody can do it his own way, and it can be experienced in an incredible variety of ways: those who experience it as a lifestyle $[\ldots]$ because climbing is their passion and they connect all the aspects of their lives with it, travelling, leisure, holidays... [...]; others who interpret it more as a competitive sport implying workout, competitive training, aiming at competitions, and therefore they don't climb outdoors [...]." (Cesco, artificial climbing hall manager and route-setter)
}

"In the majority of cases, [...] there is great reciprocal respect for, and considerable mixing between, those who came from sport climbing and moved to mountaineering, 
and those who came from mountaineering and discovered sport climbing. They are two sides of the same coin, not conflictual" (Dino, referee and instructor)

The increasing participation is welcomed as a marker of commercial success and as a source of new profit, as well as evidence of growing social visibility and recognition. The recent inclusion of sport climbing in the forthcoming edition of the Olympic Games, in this perspective, is interpreted as a possible boost to further development of the practice, capable of attracting more funding and followers.

While expressing an inclusive attitude in acknowledging the variety of legitimate ways of climbing, when suppliers of indoor climbing facilities and services talk about their own practice as expert and committed climbers, the majority of them tend to stress the distinctiveness of climbing on the rocks. Going outdoors is perceived as a more pleasurable experience than when they methodically train or compete indoors, something that can be sometimes more relaxing, sometimes more challenging.

"I go on the rocks because I love climbing and sometimes I need to get rid of all that competitive atmosphere, to be fit on the day of the contest, to manage the race, to do it once without mistakes... When I go on the rocks I am more... not relaxed, but I have a different attitude, I go there to spend a full day out doing what I love most." (Gustave, artificial climbing hall manager and route-setter)

Moreover, to attract people from indoor to outdoor climbing is, for some of these climbers, a sort of professional mission:

"I am still passionate about outdoor life, I am attending a course to become a mountain guide, to be certified to accompany people outdoors. My aim is, in the future, to be involved in indoor and sport climbing, [...] but bringing people closer to this sport $[\ldots]$ meanwhile working as a connection $[\ldots]$ with the outdoor environment, the mountains surrounding our city [...]." (Cesco, indoor climbing hall manager and rout-setter) 
Among participants with different levels of expertise (expert, amateur, novice), on the contrary, we find a more conflictual representation of the different ways of climbing and a more explicit indoor-outdoor polarisation. This opposition seems to work as a battleground for the definition of authenticity (Wheaton 2000; Beal and Weidman 2003), of who is, and what makes, a "real climber", and therefore of how to make distinctions and create hierarchies among participants (Wheaton 2007).

The interviewees insist on two dimensions of the construction of what is natural, as we have already illustrated: nature as an outdoor environment, and as a matter of a "wild", "gipsy-like” lifestyle.

First of all, participants explicitly criticize those climbers who, having learned the practice on artificial walls, don't appreciate or don't try outdoor climbing (Eden \& Barratt 2010). Restraining climbing experience to an indoor setting is described as a loss of its full (and legitimate) meaning, which is the exploration of the natural environment as well of one's own self.

\footnotetext{
"You should climb to discover, to explore... Outdoors and not only in an indoor centre." (Fiorenza, athlete)

"Surely those who climb only indoors miss the beauty of the mountains." (Antonia, expert amateur)
}

Indoor climbing as a self-referential setting risks therefore to be perceived as a closed context, with a symbolic shift from "indoor" as a neutral connotation to "artificial" as a more derogatory label. In this critical perspective, even synthetic materials (plastic, resins) become the opposite of -and not something complementary with and preparatory to - "natural" rocks. 
"Among them there are those who are just 'plastic-pitchers', people who climb only indoors. They are not interested in going outdoors because outdoors is painful, tiring, difficult, dangerous [...] Those who climb only indoors, on resin, with a comfortable crashpad below, they are the 'comfy' ones." (Mirko, expert amateur)

Indoor climbing walls, losing their connection with the natural outdoors, can be (mis)understood as an average gym centre where participants are focussed only on toning up their bodies. A muscular body is acknowledged as a distinctive marker of a climber, but it is considered as a byproduct of a practice whose aim is to probe one's embodied skills on a natural test-bench.

"Climbing started on the rocks, and those who climb only indoors, saying 'I don't like rocks' are doing a different sport, they are not climbing. They are 'plasticgrabbers'... it's like doing pull-ups but using holds instead... Therefore those who climb only indoors and never go outdoors [...] are not real climbers." (Fiorenza, athlete)

A final source of inauthenticity is the idea that climbing has become fashionable, and therefore can be approached by the typical poser, more focussed on appearance (the 'cool pose') than on attitude and commitment.

"By a real climber I mean someone who climbs for love $[\ldots]$ surely there are also inauthentic climbers who that do it as a fashion statement, because it's cool." (Francesca, expert amateur) 


\section{Discussion}

The indoorisation of climbing in Italy seems not to have engendered the double shift in the sources of, and claim-makers for, authenticity described by Salome (Salome 2010, Salome and Van Bottenburg 2012).

In fact, our analysis has revealed that reference to nature is still a relevant dimension in the way Italian climbers define themselves and give sense to their practice. However, this reference appears to be more complex and articulated than the mere outdoor/indoor binomial: we have chosen to adopt the notion of 'naturalness' to try to account for this plurality of dimensions. Consequently, we have identified three main themes: nature as an outdoor environment, naturalness as a wild lifestyle and climbing as a natural inborn motor scheme.

Moreover, by giving voice to both suppliers and participants, the analysis has shown that the struggle for authenticity is still going on among climbers.

According to Salome (2010), also the suppliers of indoor facilities we interviewed seem to adopt a more inclusive attitude towards the increasing variety of climbing styles and types of participants, thereby blurring the hierarchical distinctions between hardcore participants and newbies, wannabees, posers, and outsiders (Donnelly 2006). For this reason, they can be compared with the emerging type of participants Salome and Van Bottenburg (2012) named "exceeders", combining the use of training in artificial settings with the search for a full experience in outdoor settings: a type of participants that the two scholars significantly described as "the most devoted and enthusiastic group with regard to their sports" (ibid., 37), with a high proportion of climbers.

However, as we have seen, when Italian suppliers move the focus of their attention from a professional perspective to their personal experience as expert and committed climbers, they tend to emphasize climbing on the rocks and outdoor life (Rickly-Boyd 2012) as a meaningful and vital aspect of their practice, without making an explicit 
authenticity claim. We can provide a different interpretation of this outcome: on the one hand, we could follow Salome (2010) in saying that, for indoor suppliers, hierarchies among practitioners have become less relevant; on the other hand, since the suppliers we interviewed have a multilayered professional profile (Dumont 2016) - i.e. indoor centre managers and/or route-setters and/or instructors - they have such an established reputation within the local and national climbing community that they don't require any claim for their authenticity, which seems to be embodied and taken for granted.

Moving on to participants, we have found similarities with and differences from Salome and Van Bottemburg (2012). As in the Netherlands, in North-Western Italy climbing has become a more diversified practice including mainly-indoor, mainlyoutdoor and both-indoor-and-outdoor practitioners. By qualitatively in-depth exploring how different kinds of participants make sense of their climbing experience, however, some tensions, boundaries and hierarchies are re-emerging.

The naturalness of the outdoor context of practice and of a climbing-focussed wild lifestyle is evoked as a marker of the real - committed, passionate, engaged - climber (Kiewa 2002) when practitioners talk about their own experiences (cfr. section 4). At the same time, the lack of those two dimensions of naturalness is mobilized to label the (in)authenticity of those practitioners who, treating climbing as a sport like any other (Challeat 2014), risk de-naturalising it.

To conclude, the investigation of Italian climbers' (both indoor facilities suppliers and participants) has problematized the impact of indoorisation on climbing as a practice, showing that, at least in the Italian context, the reference to naturalness is still a core dimension of rock climbing (Krein 2014): nature is not only the environment where climbing takes place but also a subject to interact with: as an opponent (the pitch to be challenged and mastered) and as a partner (the rock to be in touch and to dance with). 



\section{References}

Aubel, O. 2005. L'escalade libre en France. Sociologie d'une prophetie sportive. Paris: L'Harmattan

Aubel, O. 2002. “Les enjeux de la sportivisation de l'escalade libre.” In Deux siècles d'alpinismes européens, edited by Hoibian, O., Defrance, J., 273-291. Paris: L’Harmattan.

Beal, B., and M. M. Smith. 2010. "Maverick's: Big-Wave Surfing and the Dynamic of 'Nothing' and 'Something'." Sport in Society 13 (7-8): 1102-1116. doi: 10.1080/17430431003780047.

Beal, B., and L. Weidman. 2003. "Skateboarding and Authenticity." In To the Extreme: Alternative Sports, Inside and Out, edited by Rinehart, R. E., and S. Sydnor, 337-352. New York: Suny Press.

Bogardus, L. M. 2012. "The Bolt Wars: A Social Worlds Perspective on Rock Climbing and Intragroup Conflict.” Journal of Contemporary Ethnography 41 (3): 283-308. doi: $10.1177 / 089121611426429$.

Braun, V., and V. Clarke. 2006. "Using Thematic Analysis in Psychology." Qualitative Research in Psychology 3 (2): 77-101. doi: 10.1191/1478088706qp063oa.

Brymer, E., and T. Gray. 2010. "Developing an Intimate 'Relationship' with Nature through Extreme Sports Participation.” Leisure/Loisir 34 (4): 361-374. doi: 10.1080/14927713.2010.542888.

Challéat, S. 2014. "L'escalade, un sport comme les autres dans la course aux jeux ?" Grimper, Le magazine de l'escalade, (159): 26-30. Hal Id: hal-01150150.

Clayton, B., and E. Coates. 2015. "Negotiating the Climb: A Fictional Representation of Climbing, Gendered Parenting and the Morality of Time." Annals of Leisure Research 18 (2): 235-251. doi: 10.1080/11745398.2014.957221.

Corneloup, J., and P. Bourdeau. 2004. "Les sports de nature. Entre pratiques libres, territoires et logiques institutionnelles.” Les Cahiers Espaces 117-125. Hal Id: halshs-00377043.

Donnelly, M. 2006. "Studying Extreme Sports: Beyond the Core Participants.” Journal of Sports and Social Issues 30 (2): 219-224. doi: 10.1177/0193723506287187.

Dumont, G. 2017. "The Beautiful and the Damned: The Work of New Media Production in Professional Rock Climbing.” Journal of Sport and Social Issues 41 (2): 99-117. doi: $10.1177 / 0193723516686285$.

Dumont, G. 2016. "Multi-layered Labor: Entrepreneurship and Professional Versatility in Rock Climbing." Ethnography 17 (4): 440-459. doi: 10.1177/1466138116638677.

Eden, S., and P. Barratt. 2010. “Outdoors versus Indoors? Angling Ponds, Climbing Walls and Changing Expectations of Environmental Leisure." Area 42 (4): 487-493. doi: $10.1111 / \mathrm{j} .1475-4762.2010 .00943$. 
Giannoulakis, C. 2016. “The 'Authenticitude' Battle in Action Sports: A Case-based Industry Perspective.” Sport Management Review 19: 171-182. doi: 10.1016/j.smr.2015.05.004. Humberstone, B. 2011. "Embodiment and Social and Environmental Action in Nature-based Sport: Spiritual Spaces." Leisure Studies $30 \quad$ (4): 495-512. doi: 10.1080/02614367.2011.602421.

Kiewa, J. 2002. "Traditional Climbing: Metaphor of Resistance or Metanarrative of

Oppression?” Leisure Studies 21 (2): 145-161. doi:10.1080/02614360210158605.

King, K., and A. Church. 2013. “ 'We Don't Enjoy Nature like That': Youth Identity and Lifestyle in the Countryside." Journal of Rural Studies 31: 67-76. doi: 10.1016/j.jrurstud.2013.02.004.

Krein, K. J. 2014. "Nature Sports." Journal of the Philosophy of Sport 41 (2): 193-208. doi: $10.1080 / 00948705.2013 .785417$.

Kulczycki, C. 2014. "Place Meanings and Rock Climbing in Outdoor Settings." Journal of Outdoor Recreation and Tourism 7-8: 8-15. doi: 10.1016/j.jort.2014.09.005.

Lewis, N. 2000. "The Climbing Body, Nature and the Experience of Modernity." Body \& society 6 (3-4): 58-80. doi: 10.1177/1357034x00006003004.

Patton, M. 1990. Qualitative Evaluation and Research Methods. Beverly Hills: Sage.

Rickly-Boyd, J. 2012. "Lifestyle Climbing: Toward Existential Authenticity.” Journal of Sport \& Tourism 17 (2): 85-104. doi: 10.1080/14775085.2012.729898.

Peterson, R. A. 2005. "In Search of Authenticity.” Journal of Management Studies 42 (5): 1083 1098. doi: 10.1111/j.1467-6486.2005.00533.x.

De Melo, R. J. E. S., and A. M. R. Gomes. 2016. "Understanding Nature Sports Organizations in Portugal." The Open Sports Sciences Journal 9 (Suppl-1,M3): 13-25. doi: $10.2174 / 1875399$ X01609010013.

Salome, L. 2010. "Constructing Authenticity in Contemporary Consumer Culture: The Case of Lifestyle Sports." European Journal for Sport and Society 7: 69-87. doi: 10.1080/16138171.2010.11687846.

Salome, L., and M. Van Bottenburg. 2012. “Are They all Daredevils? Introducing a Participation Typology for the Consumption of Lifestyle Sports in Different Settings.” European Sport Management Quarterly 12 (1): 19-42. doi: 10.1080/16184742.2011.637171.

Sterchele, D., and R. Ferrero Camoletto. 2017. "Governing Bodies or Managing Freedom? Subcultural Struggles, National Sport Systems and the Glocalised Institutionalisation of Parkour." International Journal of Sport Policy and Politics 9 (1): 89-105. doi: 10.108019406940.2017.1289235.

Suchet, A. 2011. "La sportivisation des pratiques, dites, nouvelles". Aspects Sociologiques 18 (1): $1-17$. 
Sparkes, A. C., and B. Smith. 2014. Qualitative Research Methods in Sport, Exercise and Health. From Process to Product. London: Routledge.

Stoddart, M. C. 2011. "Constructing Masculinized Sportscapes: Skiing, Gender and Nature in British Columbia, Canada." International Review for the Sociology of Sport 46 (1): 108124. doi: $10.1177 / 1082690210373541$.

Vanreusel, B. 2002. "Naar een socio-economische visie op sportbeoefening in de natuur: van Bambi tot Rambo.” In Sportsociologie. Het spel en de spelers, edited by P. De Knop, B. Vanreusel \& J. Scheerder, Eds., 178-186. Maarssen: Elsevier Gezondheids-zorg.

Van Bottenburg, M., and L. Salome. 2010. "The Indoorisation of Outdoor Sports: an Exploration of the Rise of Lifestyle Sports in Artificial Settings." Leisure Studies 29 (9): 143-160. doi: 10. $1080 / 02614360903261479$.

Wang, N. 1999. "Rethinking Authenticity in Tourism Experience." Annals of Tourism Research 26 (2): 349-370. doi: 10.1016/S0160-7383(98)00103-0.

Wheaton, B. 2007. “After Sport Culture: Rethinking Sport and Post-subcultural Theory.” Journal of Sport and Social Issues 31 (3): 283-307. doi: 10.1177/0193723507301049.

Wheaton, B. 2000. “Just Do It': Consumption, Commitment, and Identity in the Windsurfing Subculture." Sociology of Sport Journal 17 (3): 254-274. doi: 10.1123/ssj.17.3.254.

Wheaton, B., and B. Beal. 2003. “'Keeping It Real': Subcultural Media and the Discourses of Authenticity in Alternative Sport.” International Review for the Sociology of Sport 38 (2): 155-176. doi:10.1177/1012690203038002002.

Williams, R. and H. Copes. 2005. “ 'How Edge Are You?' Constructing Authentic Identities and Subcultural Boundaries in a Straightedge Internet Forum." Symbolic interaction 28 (1): 6789. doi: 10.1525/si.2005.28.1.67. 
' For an analysis of the authentication process, in Italy, of a recently emerged lifestyle sport, parkour, see Sterchele and Ferrero Camoletto (2017).

ii Another example of an authenticity claim in climbing is provided by Clayton and Coates's (2015) analysis of narratives of parents who still climb "seriously".

iii Dupont (2014) provides an analysis of the different forms of participation in skateboarding.. For an exploration of the new forms of multi-layered professionalisation in rock climbing, see Dumont $(2016,2017)$.

${ }^{i v}$ We want to thank Chiara Canova (interviews 15-36) and Matteo De Costanzi (interviews 1-14), the two Masters students who made their empirical material available to us and authorized our analysis for this article. In the sample, female participants are overrepresented because Chiara Canova's Masters research project was focussed on the construction of femininities in rock climbing. We have tried to partially balance this sample composition by interviewing, in the follow-up research, mainly male indoor climbing facilities suppliers.

${ }^{v}$ The distinction between the different levels of expertise was constructed by taking into account how many years the subject had been climbing and what kind of climbing experiences he or she had captured.

vi Despite the different lists of questions used as guideline in the three research projects, there were many shared topics under investigation.

vii Source: http://blog.earthtreksclimbing.com/volumes-the-new-dimensions-of-indoor-climbing. See also: http://blog.momentumclimbing.com/innovations-in-climbing-volumes/.

viii Source: http://blog.earthtreksclimbing.com/volumes-the-new-dimensions-of-indoor-climbing. 